\title{
Single Nucleotide Polymorphism of IL4C-590T and IL4RA 175V and Immunological Parameters in Egyptian Asthmatics with Different Clinical Phenotypes
}

Magdy Zedan*, Ashraf Bakr, Basma Shouman, Hosam Zaghloul, Mohammad Al-Haggar, Mohamed Zedan and Amal Osman Mansoura Faculty of Medicine, Mansoura, Egypt

\begin{abstract}
Objectives: Circulating cytokines and genetic patterns may help to discriminate certain asthma phenotypes.

Methods: Eighty two uncontrolled asthmatic children and twenty controls were enrolled in the study. After validation of asthma symptoms, three proposed phenotypes were formed: cough, Shortness Of Breath (SOB), and cough with SOB. Measurement of pulmonary function tests, Fractional Exhaled Nitric Oxide (FENO), eosinophilic percentage, serum levels of total IgE, IL-17 and IL-9 were done. Two Single-Nucleotide Polymorphisms (SNPs) in IL4 and IL4RA were genotyped using PCR-RFLP method.
\end{abstract}

Results: Regarding SNP IL4RA-175V, cases showed heterozygous AG predominance whereas controls showed more homozygous GG genotype. Cough group showed significant decrease in both FEV1/FVC ratio in comparison to SOB and cough with SOB groups. Also, this group showed strong inverse relationship between FEV1 values and serum IL-9. In addition, there was significant increase in serum levels of IL-17 among homozygous CC compared to CT heterozygous patients of SNP IL-4C 590T in both cough group and SOB group. Cough with SOB group showed significant increase of serum levels of IL-9 when compared to cough group. Also, it showed elevated serum level of IL-9 compared to the other two phenotypes among individuals with IL4RA 175V AA and GG genotypes. SOB group showed higher prevalence of TT genotype of SNP IL-4C 590T in comparison to the cough group.

Conclusions: Our data show diversity in genotyping and cytokine profiles between asthma as a group and the proposed clinical phenotypes. This diversity clarifies the importance of classifying asthma depending on the proposed symptomatology.

Keywords: Asthma; Phenotypes; Cytokines; Polymorphism; Children; Clinical; Egyptian

\section{Introduction}

Asthma is one of the most common chronic diseases in the world. It is estimated that around 300 million people suffer from asthma worldwide and there may be an additional 100 million persons with asthma by 2025 [1]. The prevalence of bronchial asthma in the Nile Delta region of Egypt was found to be $7.7 \%$ [2].

Clinical experience and new genetic data have proved that asthma is a heterogeneous clinical syndrome in which clinical cases emerge, proceed and respond to treatments differently [3]. Determination of serum cytokine levels in asthmatic patients could have potential utility in diagnosis of asthma and certain phenotypes, in prediction of attacks, and treatment choice [4].

In addition, asthma has a strong genetic component, and genome-wide association studies have identified variations in several genes that slightly increase the risk of disease [5]. Also, recent twin studies have investigated gene-enviromental interactions [6].The strength of applying specific phenotyping in the search for asthma susceptibility genes have been previously demonstrated [7]. However, the relative contribution of these genetic variants or Single Nucleotide Polymorphisms (SNPs) to clinical endpoints remains largely unknown [8].

The addition of a genetic or blood biomarker could move a phenotype towards the evolving term of "endotype", defined as a subgrouping of disease associated with distinct functional or pathologic mechanisms [9]. Although there is a significant improvement in asthma treatment, the challenge remains to determine specific therapeutic strategy for appropriate phenotypes [10]. Thus, our hypothesis was to study the genotyping of asthmatic children with different clinical phenotypes and to evaluate the association of those genotypes with different airway inflammatory biomarkers aiming to characterize each phenotype.

\section{Materials and Methods}

This study is a cross-sectional, case-control study, comprising 20 controls (10 (7-14) years) and 82 uncontrolled atopic asthmatic children (9.5 (8-13) years). Cases and controls were recruited from Mansoura University Children Hospital, Mansoura, Egypt from 2010 to 2013. Asthma diagnosis and assessment of asthma control were done according to guidelines of global initiative for asthma management and prevention [11]. Informed consents for all participating children were obtained from their parents. The protocol of the study was approved by Ethical Committee of the Research of Mansoura Faculty of Medicine, Egypt.

The inclusion criteria for children to be part of the research were:

*Corresponding author: Magdy Zedan, Mansoura Faculty of Medicine, Post Office: 35516, Box 50, Mansoura, Egypt, Tel: 20502242526, 201223226535 Fax: 20502234092; E-mail: magdyzedan@yahoo.com

Received July 05, 2014; Accepted August 12, 2014; Published August 19, 2014

Citation: Zedan M, Bakr A, Shouman B, Zaghloul H, Al-Haggar M, et al. (2014) Single Nucleotide Polymorphism of IL4C-590T and IL4RA 175V and Immunological Parameters in Egyptian Asthmatics with Different Clinical Phenotypes. J Allergy Ther 5: 189. doi:10.4172/2155-6121.1000189

Copyright: (C) 2014 Zedan M, et al. This is an open-access article distributed under the terms of the Creative Commons Attribution License, which permits unrestricted use, distribution, and reproduction in any medium, provided the original author and source are credited. 
presence of typical asthma symptoms (cough, shortness of breath, or wheezes), improvement with pre-bronchodilator FEV1 of $\geq 12 \%$ after nebulized salbutamol, Egyptian ethnic background in 3 generations, and absence of history of respiratory tract infection within 4 weeks of enrollment, absence of corticosteroid treatment within 4 weeks , absence of antihistamines treatment within 3 months, and absence of montelukast treatment within 2 weeks of enrollment. The criteria for healthy controls were: absence of the bronchial asthma, absence of allergic diseases in family medical records, absence of any chronic illness, serum level of common $\mathrm{IgE}<100 \mathrm{IU} / \mathrm{ml}$, Egyptian ethnic background in 3 generations.

The exclusion criteria were as follows: asthmatic patients with comorbidities such as gastro-esophageal reflux, chronic cardiopulmonary disease, concurrent pneumonia, nasal polyps, obesity and patients under immunotherapy.

After clinical examination, and validation of asthma symptoms $[12,13]$, three groups were formed:

- First group included 20 asthmatic children $(9.6 \pm 1.6$ years $)$ presented solely with cough without other symptoms such as dyspnea (shortness of breath) and wheezes [14].

- Second group included 30 asthmatic children $(10.2 \pm 2.3$ years $)$ presented solely with shortness of breath (SOB) (defined by the patient or the caregiver as chest tightness, labored breathing, difficulty in drawing sufficient breath, heavy breath) [15].

- Third group included 32 asthmatic children $(9.6 \pm 1.9$ years $)$ presented with cough as a predominant symptom associated with shortness of breath.

- In each group of patients, the presenting clinical phenotype has to be persistent for 4 weeks and those who had variable clinical presentation were excluded ( 7 cases from cough group, 6 cases from SOB group, and 5 cases from cough with SOB group)

Patients and controls underwent the following:

a. Collection of relevant medical history

b. Skin prick tests (done only for cases) for house dust mites, cat and dog epithelial cells, mold and mixed pollen antigens (Omega, Canada), together with negative (saline) and positive ( $0.5 \%$ histamine $\mathrm{HCl})$ controls.

c. Fractional exhaled nitric oxide (FENO) was measured during the study visits using the Nobreath nitric oxide breath monitor (Bedfont, Egypt) according to American Thoracic Society online measurement standards adapted for children [16].

d. Pulmonary function tests were measured by spirometry and pick flourometric test for reversibility of bronchial obstruction [17].

e. Total serum $\operatorname{IgE}$ and eosinophilic percentage.

f. Cytokine profile.

g. Genotyping study.

Peripheral blood was collected from fasting participants in the morning. Serum levels of IL-17 and IL-9 were determined by ELISA (ELISA Crokit ko13207p, South Korea).

Deoxyribonucleic acid (DNA) was isolated from $2 \mathrm{ml}$ EDTA blood using a DNA extraction and purification kit (Fermentas Lithuania).
Two polymorphisms in promoter regions of the cytokines genes were analyzed (IL4 C-590T and IL4RA 175V) in the studied asthmatic children and controls. Genotyping was performed by Polymerase Chain Reaction (PCR) followed by restriction endonuclease cleavage (Figures 1 and 2). The reference sequence of SNP (rs), primers, restriction enzymes, and digested products length of each SNP are described in table 1 [18]. All primers and restriction enzymes were purchased from (Fermentas, Lithuania).

\section{Statistical analysis}

Data were processed and analyzed using the Statistical Package of Social Science (Version 10.0; SPSS, Inc., Chicago, IL). The frequency of studied allelic polymorphisms among cases was compared with that of controls describing number and percent of each and tested for positive association using Fisher's exact test (modified chi-square test) and odds ratio (OR) with a minimum level of significance of 0.05 .

Normality tests were done using the Shapiro test. Non-parametric Mann-Whitney $U$ test was applied to compare median values and parametric independent $\mathrm{T}$ test and one way ANOVA were used to compare mean values of the other quantitative values.

\section{Results}

Our study revealed statistically significant peculiarities associated with different clinical asthma phenotypes.

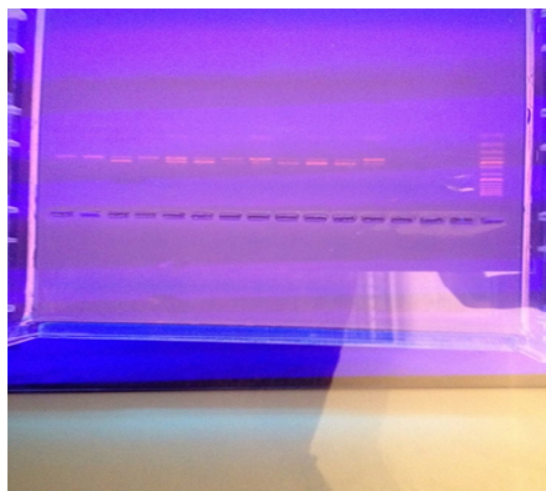

Figure 1: Bsm enzyme digestion of the amplified product of IL-4 gene, rs 243250 (C-590T polymorphysim).

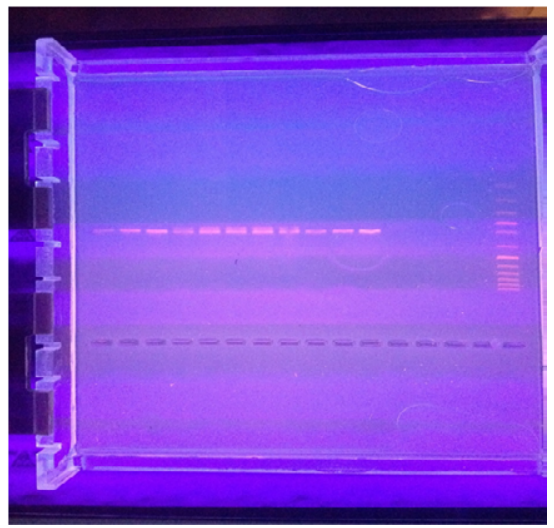

Figure 2: Rsa1 enzyme digestion of the amplified product of IL-4R gene, rs1805010 (A 175G polymorphysim). 
Citation: Zedan M, Bakr A, Shouman B, Zaghloul H, Al-Haggar M, et al. (2014) Single Nucleotide Polymorphism of IL4C-590T and IL4RA 175V and Immunological Parameters in Egyptian Asthmatics with Different Clinical Phenotypes. J Allergy Ther 5: 189. doi:10.4172/2155-6121.1000189

Page 3 of 7

\begin{tabular}{|c|c|c|c|c|}
\hline SNP name & Rs Number & Primers & Restriction enzymes & Digested product length \\
\hline IL4C-590T & 2243250 & $\begin{array}{l}\text { Forward } \\
\text { 5'>ACTAGGCCTCACCTGATACG<3' } \\
\text { Reverse } \\
\text { 5'>GTTGTAATGCAGTCCTCCTG<3' }\end{array}$ & BsmFI & $\begin{array}{l}\text { TT: } 254 \mathrm{bp} \\
\text { CC: } 210 \mathrm{bp}, 44 \mathrm{bp} \\
\text { CT: } 254 \mathrm{bp}, 210 \mathrm{bp}, 44 \mathrm{bp}\end{array}$ \\
\hline IL-4RA 175V & 1805010 & $\begin{array}{l}\text { Forward } \\
\text { 5'>GGCAGGTGTGAGGAGCATCC<3' } \\
\text { Reverse } \\
\text { 5'>GCCTCCGTTGTTCTCAGGTA<3' }\end{array}$ & Rsal & $\begin{array}{l}\text { AA: } 273 \mathrm{bp} \\
\text { GG: } 254 \mathrm{bp}, 19 \mathrm{bp} \\
\text { AG: } 273 \mathrm{bp}, 254 \mathrm{bp}, 19 \mathrm{bp}\end{array}$ \\
\hline
\end{tabular}

Table 1: Overview of the SNP [18].

\begin{tabular}{|c|c|c|c|c|}
\hline & $\begin{array}{l}\text { Cough } \\
\text { group } \\
(n=20)\end{array}$ & $\begin{array}{l}\text { Shortness of } \\
\text { breath group } \\
\quad(n=30)\end{array}$ & $\begin{array}{l}\text { Cough and } \\
\text { shortness of } \\
\text { breath group } \\
(n=32)\end{array}$ & $P$ value \\
\hline Age in years & $9.6 \pm 1.6$ & $10.2 \pm 2.3$ & $9.6 \pm 1.9$ & 0.8 \\
\hline $\begin{array}{c}\text { Duration of } \\
\text { asthma in years }\end{array}$ & $4.9 \pm 3.5$ & $6.1 \pm 3.4$ & $4.9 \pm 4$ & 0.07 \\
\hline \multicolumn{5}{|l|}{ Sex } \\
\hline Male & $16(80 \%)$ & $16(53.3 \%)$ & $20(62.5 \%)$ & 0.45 \\
\hline Female & $4(20 \%)$ & $14(46.7 \%)$ & $12(37.5 \%)$ & \\
\hline \multicolumn{5}{|l|}{ Residence } \\
\hline Rural & $16(80 \%)$ & $20(66.7 \%)$ & $25(78 \%)$ & 0.28 \\
\hline Urban & $4(20 \%)$ & $10(33.3 \%)$ & $7(22 \%)$ & \\
\hline \multicolumn{5}{|l|}{ Family history } \\
\hline Positive & $14(70 \%)$ & $22(73.3 \%)$ & $19(59.4 \%)$ & 0.61 \\
\hline Negative & $6(30 \%)$ & $8(26.7 \%)$ & $13(40.6 \%)$ & \\
\hline \multicolumn{5}{|l|}{ Allergic rhinitis } \\
\hline Positive & $7(35 \%)$ & $16(53.3 \%)$ & $17(53 \%)$ & 0.44 \\
\hline Negative & $13(65 \%)$ & $14(46.7 \%)$ & $15(47 \%)$ & \\
\hline \multicolumn{5}{|l|}{ Atopic dermatitis } \\
\hline Positive & $4(20 \%)$ & $7(23.3 \%)$ & $10(31 \%)$ & 0.64 \\
\hline Negative & $16(80 \%)$ & $23(76.7 \%)$ & $22(69 \%)$ & \\
\hline \multicolumn{5}{|l|}{ Parental smoking } \\
\hline Positive & $10(50 \%)$ & $14(46.7 \%)$ & $15(47 \%)$ & 0.7 \\
\hline Negative & $10(50 \%)$ & $16(53.3 \%)$ & $17(53 \%)$ & \\
\hline \multicolumn{5}{|l|}{ Consanguinity } \\
\hline Positive & $6(30 \%)$ & $10(33.3 \%)$ & $9(28 \%)$ & 0.36 \\
\hline Negative & $14(70 \%)$ & $20(66.6 \%)$ & $23(72 \%)$ & \\
\hline
\end{tabular}

$\mathrm{n}=$ number of subjects.

Data are expressed as mean \pm standard deviation or number (percentage of total). $P$ value assessed via one way ANOVA and Chi-square with Fisher's Exact for continuity correction.

*Statistical significance was defined as $\mathrm{P} \leq 0.05$.

Table 2: Clinical characteristics of the studied asthmatic groups.

\section{Subject characteristics}

A total of 82 children with asthma were enrolled in this study. (Table 2) These included three groups

1- Cough phenotype group (number $=20$, mean age $9.6 \pm 1.6$ ) Duration of asthma symptoms was $4.9 \pm 3.5$ years. Eighty \% of them were males and from rural areas, $70 \%$ had positive family history of allergy, most of them had negative history of allergic rhinitis and atopic dermatitis ( $65 \%$ and $80 \%$ respectively), and $70 \%$ of them had negative consanguinity.

2- SOB phenotype group (number $=20$, mean age $10.2 \pm 2.3$ ). Duration of asthma symptoms was $6.1 \pm 3.4$ years, $66.7 \%$ of them were from rural areas, no specific sex predominance, and cases with positive allergic rhinitis were $53.3 \%$.

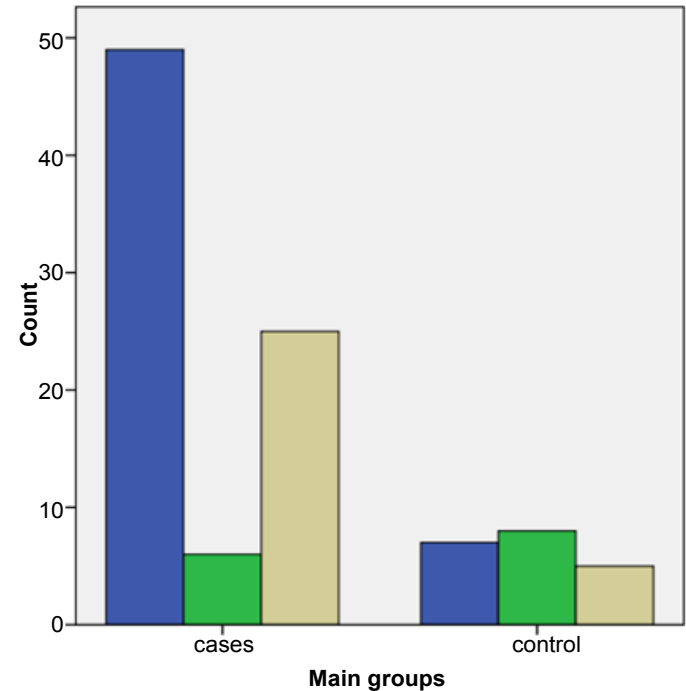

SNP IL4RA

ㅁG

पAA

Figure 3: A bar chart showing the prevalence of IL-4RA 175V genotypes in asthmatic cases and controls.

3- Cough with $\mathrm{SOB}$ phenotype group (number=20, mean age 9.6 \pm 1.9 ). Duration of asthma symptoms was $4.9 \pm 4$ years and $78 \%$ of them were from rural areas.

\section{Genotype and allele frequencies}

IL-4RA $175 \mathrm{~V}$ polymorphism: IL-4RA AG at position 175 genotype in the patient group was significantly overrepresented in comparison with the control group $(61.2 \%$ in patients vs. $35 \%$ in control, $\mathrm{P}=0.03)$ (Figure 3). In addition, this genotype was overrepresented in patients with positive family history of asthma $(66.7 \%$ in patients vs. $35 \%$ in controls, $\mathrm{P}=0.01)$ and positive allergic rhinitis $(61.2 \%$ in patients vs. $35 \%$ in control, $\mathrm{P}=0.02$ ). In contrast, the frequency of IL-4RA GG at position 175 genotype in the patient group was significantly lower than the control group $(7.5 \%$ in patients vs. $40 \%$ in controls, $\mathrm{P}=0.0007)$ (Table 3). Further, serum levels of IL-9 were found to be significantly elevated in cough with SOB phenotype group with IL-4RA AA and GG genotypes in comparison to the other three phenotypes with similar genotypes (Table 4).

IL-4 C-590T polymorphism: IL-4C -590TT genotype was found to be increased in patients compared to controls $(21.3 \%$ in patients vs. $10 \%$ in controls) but the recessive genetic model (genotype CC vs. genotype $\mathrm{CT}+\mathrm{TT}$ ) demonstrated insignificant association of the $\mathrm{CT}+\mathrm{TT}$ genotype with asthma. In addition, our study illustrated the high incidence of the $-590 \mathrm{CT}$ heterozygote genotype $(67.5 \%$ in asthmatics and $70 \%$ in controls) (Figure 4). This CT heterozygote 


\begin{tabular}{|c|c|c|c|c|c|}
\hline & \multicolumn{3}{|c|}{ Genotypes } & \multicolumn{2}{|c|}{ Alleles } \\
\hline & $\begin{array}{l}\text { GG } \\
N(\%)\end{array}$ & $\begin{array}{l}\text { AG } \\
\mathrm{N}(\%)\end{array}$ & $\begin{array}{c}\text { AA } \\
\text { N (\%) }\end{array}$ & $\begin{array}{c}\mathbf{G} \\
\mathrm{N}(\%)\end{array}$ & $\begin{array}{c}A \\
N(\%)\end{array}$ \\
\hline Control (20) & $8(40 \%)$ & $7(35 \%)$ & $5(25 \%)$ & $23(57.5 \%)$ & $17(42.5 \%)$ \\
\hline Asthmatics (80) & $6(7.5 \%)$ & $49(61.2 \%)$ & $25(31.3 \%)$ & $61(38 \%)$ & $99(62 \%)$ \\
\hline $\mathbf{P}$ & $0.0007^{\star}$ & $0.03^{*}$ & 0.5 & $0.02^{*}$ & $0.02^{*}$ \\
\hline \begin{tabular}{|l|} 
OR \\
$(95 \% \mathrm{Cl})$
\end{tabular} & $\begin{array}{c}0.12 \\
(0.03-0.4)\end{array}$ & $\begin{array}{c}2.9 \\
(1.1-8.1)\end{array}$ & $\begin{array}{c}1.4 \\
(0.4-4.2)\end{array}$ & $\begin{array}{c}0.4 \\
(0.2-0.9)\end{array}$ & $\begin{array}{c}2.2 \\
(1.1-4.4)\end{array}$ \\
\hline $\begin{array}{l}\text { Positive family } \\
\text { history (54) }\end{array}$ & $4(7.4 \%)$ & $36(66.7 \%)$ & $14(25.9 \%)$ & $44(40.8 \%)$ & $64(59.2 \%)$ \\
\hline $\mathbf{P}$ & $0.002^{*}$ & $0.01^{*}$ & 0.9 & 0.07 & 0.07 \\
\hline \begin{tabular}{|l|} 
OR \\
$(95 \% \mathrm{Cl})$
\end{tabular} & $\begin{array}{c}0.1 \\
(0.03-0.5)\end{array}$ & $\begin{array}{c}3.7 \\
(1.3-11)\end{array}$ & $\begin{array}{c}1.05 \\
(0.3-3.4)\end{array}$ & $\begin{array}{c}0.5 \\
(0.2-1.1)\end{array}$ & $\begin{array}{c}1.9 \\
(0.9-4.1)\end{array}$ \\
\hline $\begin{array}{l}\text { Positive allergic } \\
\text { rhinitis (39) }\end{array}$ & $3(7.7 \%)$ & $26(66.7 \%)$ & $10(25.6 \%)$ & $32(41 \%)$ & $46(59 \%)$ \\
\hline $\mathbf{P}$ & $0.005^{*}$ & $0.02^{*}$ & 0.9 & 0.09 & 0.09 \\
\hline \begin{tabular}{|l|} 
OR \\
$(95 \% \mathrm{Cl})$
\end{tabular} & $\begin{array}{c}0.1 \\
(0.02-0.5)\end{array}$ & $\begin{array}{c}3.7 \\
(1.2-11.5)\end{array}$ & $\begin{array}{c}1 \\
(0.3-3.6)\end{array}$ & $\begin{array}{c}0.5 \\
(0.2-1.1)\end{array}$ & $\begin{array}{c}1.9 \\
(0.9-4.2)\end{array}$ \\
\hline $\begin{array}{l}\text { Positive eczema } \\
\text { (21) }\end{array}$ & $2(9.5 \%)$ & $13(61.9 \%)$ & $6(28.6 \%)$ & $17(40.5 \%)$ & $25(59.5 \%)$ \\
\hline $\mathbf{P}$ & $0.03^{*}$ & 0.08 & 0.7 & 0.1 & 0.1 \\
\hline $\begin{array}{l}\text { OR } \\
(95 \% \mathrm{Cl})\end{array}$ & $\begin{array}{c}0.1 \\
(0.02-0.9)\end{array}$ & $\begin{array}{c}3 \\
(0.8-11)\end{array}$ & $\begin{array}{c}1.2 \\
(0.3-5)\end{array}$ & $\begin{array}{c}0.5 \\
(0.2-1.2)\end{array}$ & $\begin{array}{c}2 \\
(0.8-4.8)\end{array}$ \\
\hline
\end{tabular}

Significance using fisher's exact test. *Statistical significance was defined as $\mathrm{P} \leq$ 0.05

Table 3: Frequency of IL-4RA $175 \mathrm{~V}$ genotype and allelic polymorphisms among asthmatic cases compared to controls.

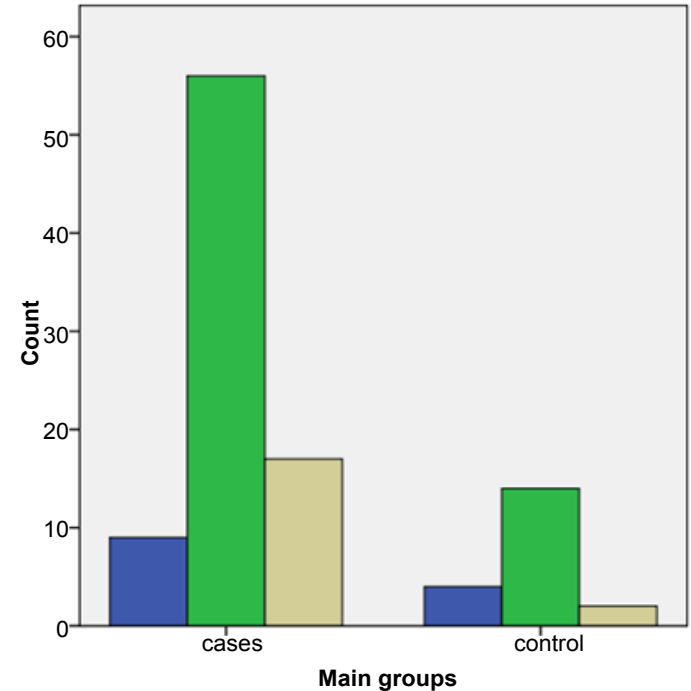

Figure 4: A bar chart showing the prevalence of IL-4 C-590T genotypes in asthmatic cases and controls.

genotype was significantly overrepresented among male patients $(\mathrm{P}=0.01, \mathrm{OR}=3.3, \mathrm{CI}=1.2-8.9)$, and the $\mathrm{TT}$ homozygote variant was significantly overrepresented among female patients $(\mathrm{P}=0.02, \mathrm{OR}=0.3$, $\mathrm{CI}=0.1-0.8$ )

In cough phenotype group and SOB phenotype group, serum IL-17 levels were found to be significantly elevated among patients with -590CC genotype as compared to those with -590CT genotype ( $\mathrm{P}=0.05,0.03$ respectively) (Table 5 ). In $\mathrm{SOB}$ phenotype group, we observed an increase of the -590TT genotype in comparison to the cough group, although not reaching the statistical significance $(\mathrm{P}=$ $0.07)$.

\section{Laboratory biomarkers and PFTs}

The median serum levels of IL-17, IL-9, total IgE, and peripheral eosinophilic percentage were significantly elevated in patients in comparison to controls ( $\mathrm{P}=0.03,0.003,<0.0001,<0.0001$ respectively). The cough with SOB group showed significant increase in serum IL-9 and peripheral eosinophilic percentage compared to cough group $(\mathrm{P}=0.02$, and 0.002 respectively) (Table 6$)$. As regard the cough group, significant decrease in FEV1/FVC ratio was noticed when compared to the other two groups $(\mathrm{P}=0.01)$. Finally, the $\mathrm{SOB}$ group showed significant increase in FENO values in comparison to the other groups $(\mathrm{P}<0.0001)$. In addition, it showed more frequent association with allergic rhinitis $(60 \%)$ and atopic dermatitis $(35 \%)$ compared to the other groups (Table 2).

\section{Discussion}

We previously hypothesized that the response of asthmatic patients to montelukast and fluticasone vary considerably according to the clinical phenotypes of the asthmatic patients [13]. Based on this, we are trying to delineate the cytokine and genotypic pattern of the different clinical asthma phenotypes in the present study

Numerous studies suggested that genetic factors may mediate a large part of heterogeneity in response to asthma medications among asthmatics [19]. Several genes have been associated with asthma and related phenotypes, including those related to Th2 pathways (interleukin IL-4, IL-13, IL-4RA) [20]. In the view of diversity of these genes, we chose IL4C-590T and IL4RA-175V to evaluate different clinical asthma phenotypes (based on symptomatology) among Egyptian children correlating their clinical and genotyping profiles with airway inflammatory biomarkers. IL-4 and IL-4RA are from the most common candidate asthma genes, positively associated with asthma in many independent studies and were thus highly implicated as true susceptibility genes for asthma-related phenotypes [21,22]. In addition, to the best of our knowledge, no previous studies were done to analyze these two SNPs in Egyptian asthmatic children.

IL-4 is a Th2 cytokine that plays an essential role in IgE regulation [23]. IL-4 acts through the IL-4 receptor (IL-4R) that consists of two subunits, $\alpha$ chain $(\mathrm{IL}-4 \mathrm{R} \alpha)$ and the $\gamma$ chain $(\gamma \mathrm{c})$. IL-4Ra is a component of both the IL- 4 and the IL-13 receptor complexes [24].

Cytokine gene polymorphisms were found to affect the serum levels of cytokines by influencing transcriptional regulation [25]. In the present study, statistically significant differences were found between the proposed asthma phenotypes in cytokine profile and genotyping distribution of IL4RA-175V and IL4C-590T. Further a different genotyping was noticed when dealing with asthma as a group and after its clinical phenotyping.

The study of $-175 \mathrm{~V}$ IL4RA polymorphism showed significant higher incidence of GG heterozygosity genotype in controls, whereas asthmatic cases as a group showed AG heterozygosity genotype. Also, asthmatic children with positive family history of allergy and positive allergic rhinitis showed significant higher prevalence of the AG heterozygosity genotype when compared to controls. This could suggest that the patient carrying the A allele of IL-4RA-175V had an increased risk for asthma. This data is consistent with previous studies [24,26]. Nevertheless, other studies showed insignificant association of this polymorphism with asthma risk [18]. On the other aspect, Cough with SOB group showed significant increase of serum levels of IL-9 among asthmatics with -175V AA homozygosity genotype and -175V GGhomozygosity genotype of IL4RA gene in comparison to 
Citation: Zedan M, Bakr A, Shouman B, Zaghloul H, Al-Haggar M, et al. (2014) Single Nucleotide Polymorphism of IL4C-590T and IL4RA 175V and Immunological Parameters in Egyptian Asthmatics with Different Clinical Phenotypes. J Allergy Ther 5: 189. doi:10.4172/2155-6121.1000189

Page 5 of 7

\begin{tabular}{|c|c|c|c|c|c|c|c|c|}
\hline \multicolumn{2}{|c|}{ Cough group } & \multicolumn{2}{|c|}{ SOB group } & \multicolumn{2}{|c|}{ Cough with SOB group } & \multicolumn{2}{|c|}{ Control } & \\
\hline IL4RA175V & IL-9 & IL4RA175V & IL-9 & IL4RA175V & IL-9 & IL4RA175V & IL-9 & \\
\hline $\mathrm{G} / \mathrm{G}(\mathrm{n}=3)$ & $29 \pm 3$ & $\mathrm{G} / \mathrm{G}(\mathrm{n}=0)$ & & $\mathrm{G} / \mathrm{G}(\mathrm{n}=3)$ & $88 \pm 58$ & $\mathrm{G} / \mathrm{G}(\mathrm{n}=8)$ & $18 \pm 4.7$ & $P=0.009^{*}$ \\
\hline$A / G(n=12)$ & $25 \pm 11$ & $\mathrm{~A} / \mathrm{G}(\mathrm{n}=18)$ & $35 \pm 17$ & $A / G(n=20)$ & $39 \pm 29$ & $\mathrm{~A} / \mathrm{G}(\mathrm{n}=7)$ & $34 \pm 14$ & $P=0.1$ \\
\hline \multirow[t]{2}{*}{$A / A(n=5)$} & $28 \pm 17$ & $\mathrm{~A} / \mathrm{A}(\mathrm{n}=12)$ & $29 \pm 11$ & $A / A(n=9)$ & $85 \pm 65$ & $A / A(n=5)$ & $42 \pm 15$ & $P=0.05^{*}$ \\
\hline & $P=0.8$ & & $P=0.7$ & & $P=0.3$ & & $P=0.4$ & \\
\hline IL4C-590T & IL-17 & IL4C-590T & IL-17 & IL4C-590T & IL-17 & IL4C-590T & IL-17 & \\
\hline$C / C(n=3)$ & $267 \pm 109$ & $C / C(n=3)$ & $263 \pm 240$ & $C / C(n=3)$ & $65 \pm 50$ & $C / C(n=4)$ & $79 \pm 7.1$ & $P=0.2$ \\
\hline$C / T(n=15)$ & $120 \pm 88$ & $C / T(n=17)$ & $108 \pm 72$ & $C / T(n=24)$ & $154 \pm 146$ & $C / T(n=14)$ & $88 \pm 15$ & $P=0.3$ \\
\hline \multirow[t]{2}{*}{$T / T(n=2)$} & $57 \pm 28$ & $T / T(n=10)$ & $129 \pm 73$ & $\mathrm{~T} / \mathrm{T}(\mathrm{n}=5)$ & $137 \pm 65$ & $\mathrm{~T} / \mathrm{T}(\mathrm{n}=2)$ & $103 \pm 38$ & $P=0.5$ \\
\hline & $\begin{array}{c}\mathrm{P}=0.06 \\
\mathrm{P} \sqcap=0.04^{*}\end{array}$ & & $P=0.5$ & & $P=0.3$ & & $P=0.5$ & \\
\hline
\end{tabular}

Results are expressed as mean \pm Standard deviation.

$P$ value based on one way ANOVA, and independent sample $T$ test

*Statistical significance was defined as $\mathrm{P} \leq 0.05$.

$\mathrm{P} \sqcap$ for difference between CC, CT is significant $\left(0.04^{*}\right)$

Table 4: Serum levels of IL-9 and IL-17 cytokines $(\mathrm{pg} / \mathrm{ml})$ in individuals with different genotypes of the IL-4RA $175 \mathrm{~V}$ and IL-4C-590T genes in the three asthmatic phenotypes.

\begin{tabular}{|c|c|c|c|c|c|}
\hline \multicolumn{4}{|c|}{ Genotypes } & \multicolumn{2}{|c|}{ Alleles } \\
\hline & $\begin{array}{c}\text { CC } \\
\text { N (\%) }\end{array}$ & $\begin{array}{c}\text { CT } \\
\text { N (\%) }\end{array}$ & $\begin{array}{c}\text { TT } \\
\text { N (\%) }\end{array}$ & $\begin{array}{c}\mathrm{C} \\
\mathrm{N}(\%)\end{array}$ & $\begin{array}{c}T \\
N(\%)\end{array}$ \\
\hline \multicolumn{6}{|l|}{ Family history } \\
\hline Positive (54) & $7(13 \%)$ & $38(70.4 \%)$ & $9(16.7 \%)$ & $52 / 108(48.1 \%)$ & $56 / 108(51.8 \%)$ \\
\hline Control (20) & $4(20 \%)$ & $14(70 \%)$ & $2(10 \%)$ & $22 / 40(55 \%)$ & $18 / 40(45 \%)$ \\
\hline $\mathbf{P}$ & 0.45 & 0.9 & 0.4 & 0.4 & 0.4 \\
\hline OR, (95\%Cl) & $\begin{array}{c}0.59 \\
(0.15-2.3)\end{array}$ & $\begin{array}{c}1.01 \\
(0.3-3.1)\end{array}$ & $\begin{array}{c}1.8 \\
(0.3-9.1)\end{array}$ & $\begin{array}{c}0.76 \\
(0.3-1.6)\end{array}$ & $\begin{array}{c}1.3 \\
(0.6-2.7)\end{array}$ \\
\hline \multicolumn{6}{|c|}{ Allergic rhinitis } \\
\hline Positive (39) & $3(7.7 \%)$ & $28(71.8 \%)$ & $8(20.5 \%)$ & $34 / 78(43.5 \%)$ & $44 / 78(56.4 \%)$ \\
\hline Control (20) & $4(20 \%)$ & $14(70 \%)$ & $2(10 \%)$ & $22 / 40(55 \%)$ & $18 / 40(45 \%)$ \\
\hline $\mathbf{P}$ & 0.2 & 0.8 & 0.3 & 0.24 & 0.24 \\
\hline OR, $(95 \% \mathrm{Cl})$ & $\begin{array}{c}0.3 \\
(0.06-1.6)\end{array}$ & $\begin{array}{c}1.1 \\
(0.3-3.5)\end{array}$ & $\begin{array}{c}2.3 \\
(0.4-12.1)\end{array}$ & $\begin{array}{c}0.6 \\
(0.3-1.4)\end{array}$ & $\begin{array}{c}1.6 \\
(0.7-3.4)\end{array}$ \\
\hline \multicolumn{6}{|l|}{ Eczema } \\
\hline Positive (21) & $2(9.5 \%)$ & $15(71.4 \%)$ & $4(19 \%)$ & $19 / 42(45.2 \%)$ & $23 / 42(54.7 \%)$ \\
\hline Control (20) & $4(20 \%)$ & $14(70 \%)$ & $2(10 \%)$ & $22 / 40(55 \%)$ & $18 / 40(45 \%)$ \\
\hline $\mathbf{P}$ & 0.3 & 0.9 & 0.4 & 0.37 & 0.37 \\
\hline OR, $(95 \% \mathrm{Cl})$ & $\begin{array}{c}0.4 \\
(0.06-2.6)\end{array}$ & $\begin{array}{c}1.1 \\
(0.3-4.1)\end{array}$ & $\begin{array}{c}2.1 \\
(0.3-13)\end{array}$ & $\begin{array}{c}0.67 \\
(0.3-1.6)\end{array}$ & $\begin{array}{c}1.4 \\
(0.6-3.5)\end{array}$ \\
\hline \multicolumn{6}{|c|}{ Allergic march } \\
\hline Positive (17) & $1(5.9 \%)$ & $12(70.6 \%)$ & $4(23.5 \%)$ & $14 / 34(41.2 \%)$ & $20 / 34(58.8 \%)$ \\
\hline Control (20) & $4(20 \%)$ & $14(70 \%)$ & $2(10 \%)$ & $22 / 40(55 \%)$ & $18 / 40(45 \%)$ \\
\hline $\mathbf{P}$ & 0.2 & 0.9 & 0.3 & 0.23 & 0.23 \\
\hline OR, (95\%Cl) & $\begin{array}{c}0.25 \\
(0.02-2.4)\end{array}$ & $\begin{array}{c}1.02 \\
(0.2-4.2)\end{array}$ & $\begin{array}{c}2.7 \\
(0.4-17.4)\end{array}$ & $\begin{array}{c}0.57 \\
(0.2-1.4)\end{array}$ & $\begin{array}{c}1.7 \\
(0.7-4.4)\end{array}$ \\
\hline \multicolumn{6}{|c|}{ Parental smoking } \\
\hline Positive (38) & $4(10.5 \%)$ & $26(68.4 \%)$ & $8(21.1 \%)$ & $34 / 76(44.7 \%)$ & $42 / 76(55.3 \%)$ \\
\hline Control (20) & $4(20 \%)$ & $14(70 \%)$ & $2(10 \%)$ & $22 / 40(55 \%)$ & $18 / 40(45 \%)$ \\
\hline $\mathbf{P}$ & 0.3 & 0.9 & 0.3 & 0.3 & 0.3 \\
\hline OR, $(95 \% \mathrm{Cl})$ & $\begin{array}{c}0.47 \\
(0.1-2.1)\end{array}$ & $\begin{array}{c}0.9 \\
(0.3-3)\end{array}$ & $\begin{array}{c}2.4 \\
(0.4-12.5)\end{array}$ & $\begin{array}{c}0.6 \\
(0.3-1.4)\end{array}$ & $\begin{array}{c}1.5 \\
(0.7-3.2)\end{array}$ \\
\hline
\end{tabular}

Significance using fisher's exact test

*Statistical significance was defined as $\mathrm{P} \leq 0.05$.

Table 5: Frequency of IL-4 C-590T genotype and allelic polymorphisms among asthmatic cases compared to controls with their statistical significance.

other phenotypes of similar genotype. Thus, asthma as a group showed AG heterozygosity genotype, whereas cough with SOB group showed AAand GG homozygosity genotype. In turn, phenotyping based on symptomatology makes a sense in endotyping of asthma, which may have a reflection on heterogeneity in response to asthma medications.

\begin{tabular}{|l|c|c|c|}
\hline & Cough group & $\begin{array}{c}\text { Cough and SOB } \\
\text { group }\end{array}$ & $\boldsymbol{P}$ value \\
\hline Serum IL-17 (pg/ml) & $99(74-167)$ & $117(83-160)$ & 0.84 \\
\hline Serum IL-9 (pg/mI) & $26.1 \pm 11.9$ & $50 \pm 43$ & $\mathbf{0 . 0 2}^{\star}$ \\
\hline Serum IgE (IU/ml) & $293(100-605)$ & $241(97-512)$ & 0.9 \\
\hline Eosinophilic \% & $1(1-2)$ & $3(2-4)$ & $\mathbf{0 . 0 0 2}^{*}$ \\
\hline
\end{tabular}

SOB: Shortness of breath; IL: Interleukin; pg: Picogram; IgE: Immunoglobulin E. Data are expressed as median (range) and mean \pm standard deviation $P$ value based on Mann-Whitney test and independent T-test *Statistical significance was defined as $\mathrm{P} \leq 0.05$

Table 6: Biochemical markers of cough group versus cough and shortness of breath group.

The study of C-590T IL4 polymorphism showed none statistically significant differences between Egyptian asthmatic children and the control group as regard genotype and allelic frequency. However, the prevalence of the mutant variant genotype TT was minimal in the control group and more common in the affected children. Previous reports have shown that IL-4 C-589T polymorphism influences asthma risk in a most probable dominant model, i.e., one $-589 \mathrm{~T}$ allele has adequate capacity to enhance the asthma risk of susceptible individuals [23]. Also, a previous meta-analysis observed the association between $-589 \mathrm{C} / \mathrm{T}$ polymorphism and asthma among Asians and Caucasians but not among African Americans [26]. Our results go hand in hand with this trend. Nevertheless, the difference was not statistically significant. This may be related to different genetic and environmental backgrounds in populations of different nationalities.

Interestingly, cough group and $\mathrm{SOB}$ group revealed significant increase in serum levels of IL-17 among patients with CC homozygote variant of IL-4C 590T compared to patients with CT heterozygote variant. Whereas, non significant association was found between IL-4 polymorphism at position C-590 and asthma as a group. In addition, the SOB group showed higher prevalence of the mutant variant genotype TT in comparison to the cough group, although, not reaching the statistical significance. The study of C-590T IL4 polymorphism also showed the high incidence of the CT heterozygote variant $(67.5 \%$ in asthmatics and $70 \%$ in controls). This is consistent with previous study done by Amirzargar et al., 2009 [25]. However, Smolnikova et al., 2013 found higher incidence of the CC homozygote variant [27]. Regarding gender, there was significant higher frequency of the CT heterozygote variant among male Egyptian asthmatic patients and significant higher 
Citation: Zedan M, Bakr A, Shouman B, Zaghloul H, Al-Haggar M, et al. (2014) Single Nucleotide Polymorphism of IL4C-590T and IL4RA 175V and Immunological Parameters in Egyptian Asthmatics with Different Clinical Phenotypes. J Allergy Ther 5: 189. doi:10.4172/2155-6121.1000189

Page 6 of 7

frequency of the TT homozygote variant among female patients. To the best of our knowledge, this is the first study that analyzes IL4C-590T and IL4RA-175V gene polymorphisms among Egyptian asthmatic children.

Cough with SOB group showed significant increase in both serum IL-9 levels and peripheral eosinophilic percentage when compared to cough phenotype group. Also, this phenotype showed a strong significant positive relationship between eosinophilic percentage and FENO values $(\mathrm{P}=0.02)$. In addition, in this group eosinophilic percentage was positively associated with IL-9, however, not reaching the statistical significance $(\mathrm{P}=0.08)$. IL- 9 appears to carry on a major role in mediating mast cells survival and function [28]. Further, SNPs in IL4RA were found to be associated with severe asthma exacerbations, lower lung function, and increased mast cell-related tissue inflammation [20].

Mast cells may influence the development of airway remodeling in asthma by releasing large amounts of plasminogen activator inhibitor type 1. Also, many studies have suggested that IL-9 may play an important role in airway remodeling in asthma especially in the early initiation of this remodeling, but other cell types likely contribute later. It was speculated that susceptibility to exacerbation may be mediated partly by developed airway remodeling in subgroup of patients with asthma [29].

In addition to the known inhibitory effect of long acting $\beta 2$ agonists (LABA) on mast cell proliferation [30], many studies have highlighted the importance of them in suppressing collagen deposition, and reducing airway remodeling with enhanced effect in combination with inhaled corticosteroids [31]. Thus, cough with SOB phenotype characterized by raised serum IL-9 levels, which is inversely correlated to FEV1 values, and in turn increased mast cell activation, IgE production, and airway hyperresponsiveness, denotes severity of the patient presentation, and increased risk to recurrent acute exacerbations. The characteristics of the cough with SOB phenotype group described in the present study could have potential clinical and therapeutic implications. It could be logic to postulate that this phenotype is at risk of frequent exacerbations and sounding airway remodeling. Thus, the use of LABA as an add-on therapy when needed in this phenotype may have an upper hand than other therapeutic options. Thus, it seems reasonable to hypothesize that each presenting clinical symptom in asthmatic patients has its own cytokine pathway and its specific genetic makeup.

The SOB phenotype group showed significant increase in FENO when compared to the other two studied phenotypes. Also, they showed more frequent association with allergic rhinitis (60\%) and atopic dermatitis (35\%) compared to the other groups. This may highlight the feature of allergic march in this phenotype.

In conclusion, our proposed clinical asthma phenotypes express a significant value in detection of specific cytokine and genotype profiles for asthma; hence this may help in prediction and diagnosis of clinical asthma phenotypes which might have a potential value in tailoring asthma therapies.

\section{Limitations of the Study}

We used costly investigations and that has limited the number of studied patients. Nevertheless, our future genetic studies are going to include larger sample size.

\section{Author Contributions}

Magdy Zedan and Amal Osman: Design and final revision of data and article

Hussam Zaghloul: Laboratory analysis and results discussion

Ashraf Bakr, Basma Shouman, Mohammad Al-Haggar and Mohamed Zedan: Statistical analysis and final revision of article.

\section{References}

1. Bijanzadeh M, Mahesh PA, Ramachandra NB (2011) An understanding of the genetic basis of asthma. Indian J Med Res 134: 149-161.

2. Zedan M, Settin A, Farag M, Ezz-Elregal M, Osman E (2009) Prevalence of Bronchial asthma among Egyptian school children. Egypt J Bronchol 3:124-130

3. Hopkin JM (2012) The diagnosis of asthma, a clinical syndrome. Thorax 67 660-662.

4. Pukelsheim K, Stoeger T, Kutschke D, Ganguly K, Wjst M (2010) Cytokine profiles in asthma families depend on age and phenotype. PLoS One 5: e14299.

5. Martinez FD, Vercelli D (2013) Asthma. Lancet 382: 1360-1372.

6. Kahr N, Naeser V, Stensballe LG, Kyvik KO, Skytthe A, et al. (2014) Geneenvironment interaction in atopic diseases: a population-based twin study of early-life exposures. Clin Respir J.

7. Bønnelykke K, Sleiman P2, Nielsen K3, Kreiner-Møller E4, Mercader JM5, et al. (2014) A genome-wide association study identifies CDHR3 as a susceptibility locus for early childhood asthma with severe exacerbations. Nat Genet 46 : $51-55$

8. Tulah AS, Holloway JW, Sayers I (2013) Defining the contribution of SNPs identified in asthma GWAS to clinical variables in asthmatic children. BMC Med Genet 14: 100.

9. Wenzel SE (2013) Complex phenotypes in asthma: current definitions. Pulm Pharmacol Ther 26: 710-715.

10. Kukulj S, SerdareviÄł M2, PopoviÄł-Grle S2 (2013) Pharmacotherapy of severe asthma. Lijec Vjesn 135: 268-273.

11. Global Initiative for Asthma (2012) Global strategy for asthma management and prevention

12. Manual for the International Study of Asthma and Allergies in Childhood (ISAAC) (1992) ISAAC Coordinating Committee, Bochum and Auckland.

13. Zedan M, Gamil N, El-Chennawi F (2009) Evaluation of Different Asthma Phenotype Responses to Montelukast Versus Fluticasone Treatment. Pediatric Asthma, Allergy \& Immunology 22: 63-68.

14. Niimi A, Matsumoto $H$, Mishima $M$ (2009) Eosinophilic airway disorders associated with chronic cough. Pulm Pharmacol Ther 22: 114-120.

15. Zedan M, Attia G, Zedan MM (2013) Clinical asthma phenotypes and therapeutic responses. ISRN Pediatr: 824781

16. Dweik RA, Boggs PB, Erzurum SC, American Thoracic Society Committee on Interpretation of Exhaled Nitric Oxide Levels (FENO) for Clinical Applications (2011) An official ATS clinical practice guideline: interpretation of exhaled nitric oxide levels (FENO) for clinical applications. Am J Respir Crit Care Med 184: 602-615.

17. Pellegrino R, Viegi G, Brusasco V, Crapo RO, Burgos F, et al. (2005) Interpretative strategies for lung function tests. Eur Respir J 26: 948-968.

18. Li H, Xiaoyan D, Quanhua L, Jie L, Yixiao B (2009) Single-nucleotide polymorphisms in genes predisposing to asthma in children of Chinese Han nationality. J Investig Allergol Clin Immunol 19: 391-395.

19. Almomani B, Hawwa AF, Millership JS, Heaney L, Douglas I, et al. (2013) Can certain genotypes predispose to poor asthma control in children? A pharmacogenetic study of 9 candidate genes in children with difficult asthma. PLoS One 8: e60592.

20. Wenzel SE, Balzar S, Ampleford E, Hawkins GA, Busse WW, et al. (2007) IL4R alpha mutations are associated with asthma exacerbations and mast cell/lgE expression. Am J Respir Crit Care Med 175: 570-576.

21. Postma DS, Kerkhof M, Boezen HM, Koppelman GH (2011) Asthma and chronic obstructive pulmonary disease: common genes, common environments? Am J Respir Crit Care Med 183: 1588-1594. 
Citation: Zedan M, Bakr A, Shouman B, Zaghloul H, Al-Haggar M, et al. (2014) Single Nucleotide Polymorphism of IL4C-590T and IL4RA 175V and Immunological Parameters in Egyptian Asthmatics with Different Clinical Phenotypes. J Allergy Ther 5: 189. doi:10.4172/2155-6121.1000189

22. Andiappan AK, Nilsson D, Halldén C, Yun WD, Säll T, et al. (2013) Investigating highly replicated asthma genes as candidate genes for allergic rhinitis. BMC Med Genet 14: 51

23. Liu S, Li T, Liu J (2012) Interleukin-4 rs2243250 polymorphism is associated with asthma among Caucasians and related to atopic asthma. Cytokine 59: 364-369.

24. Isidoro-García M, Dávila I, Laffond E, Moreno E, Lorente F, et al. (2005) Interleukin-4 (IL4) and Interleukin-4 receptor (IL4RA) polymorphisms in asthma: a case control study. Clin Mol Allergy 3: 15.

25. Amirzargar AA, Movahedi M, Rezaei N, Moradi B, Dorkhosh S, et al. (2009) Polymorphisms in IL4 and iLARA confer susceptibility to asthma. J Investig Allergol Clin Immunol 19: 433-438.

26. Nie W, Zang Y, Chen J, Xiu Q (2013) Association between interleukin-4 receptor Ît chain (IL4RA) I50V and Q551R polymorphisms and asthma risk: an update meta-analysis. PLoS One 8: e69120.

27. Smolnikova MV, Smirnova SV, Freidin MB, Tyutina OS (2013) Immunologica parameters and gene polymorphisms (C-590T IL4, C-597A IL10) in severe bronchial asthma in children from the Krasnoyarsk region, West Siberia. Int $J$ Circumpolar Health 72

28. Kearley J, Erjefalt JS, Andersson C, Benjamin E, Jones CP, et al. (2011) IL-9 governs allergen-induced mast cell numbers in the lung and chronic remodeling of the airways. Am J Respir Crit Care Med 183: 865-875.

29. Kudo M, Ishigatsubo Y, Aoki I (2013) Pathology of asthma. Front Microbiol 4 263.

30. Johnson M (2002) Effects of beta2-agonists on resident and infiltrating inflammatory cells. J Allergy Clin Immunol 110: S282-290.

31. Roth M, Zhong J, S'ng C, Tamm M (2012) Formoterol and fluticasone reduce the deposition of pro-inflammatory collagens. Eur Respir J 40: abstract 2182 